\title{
Implementation of Cloud Computing for SMEs
}

\author{
Muhammad Adeel Javaid \\ Member Vendor Advisory Council, CompTIA \\ *Corresponding Author: ajaviad@gmail.com
}

Copyright $(0) 2014$ Horizon Research Publishing All rights reserved.

\begin{abstract}
Cloud computing is becoming more and more popular, especially for businesses and organizations. A lot of enterprises are shifting to the clouds because it offers a lot of benefits. With cloud computing, SMEs no longer have to maintain software and servers on their premises. There is no need to employ highly technical personnel to maintain the IT infrastructure. What businesses do now is that they rent a space on a server located anywhere in the world so that they can access their software applications. A lot of large businesses have moved to the clouds and it is expected that small and medium-sized businesses will follow suit.

SMEs can enjoy a lot of benefits when they shift to the clouds. One of such benefits is that they can save on costs. There is no need to invest on hardware and not use it fully. With cloud computing, SMEs can pay only for what they have utilized. They have the option to choose the kind of service level they require. Cloud computing service providers take care of IT support, licenses, and costly equipment. They also ensure that they have the newest software versions installed on their systems. Thus, SMEs need not worry about software installations and updates. Also, cloud computing service providers employ IT experts who can help users with their needs. The aim of this research work is to provide an overview of the implementation of cloud computing for Small and Medium Enterprises to help them make strategic decisions regarding the adoption of cloud computing within their own environment.
\end{abstract}

Keywords Cloud Computing, Strategic Analysis, PEST Analysis, Technology Adoption, Small to Medium-Sized Enterprises, SME, Qualitative Research Methods, Scoping Review

\section{Introduction}

In order to determine the viability and efficiency of Cloud Computing for SMEs and any other potential benefits, this study will look at the political, economic, social and technological factors concerning $\mathrm{CC}$ adoption. The aim is to identify the most relevant studies and see if $\mathrm{CC}$ adoption in an ICT sense does add value for SMEs.

SMEs will not normally have a large ICT department or budget, so they are not likely to have access to sophisticated
IT architectures and supporting tools. CC appears to be the solution to many of their business requirements, while at the same time avoiding conventional IT maintenance costs. CC allows them to improve IT support for their commercial activities and keep pace with new technologies [Dimitrakos 2010]. The following paragraphs introduce some of the main concepts at stake in this paper, namely Cloud Computing, SME and PEST.

Cloud Computing is a new IT consumer delivery model that aims to provide high availability and easy access [Li et al. 2009; Marta et al. 2011; Sheng-Yuan et al. 2010]. As referred to in the National Institute of Standards and Technology (NIST) definition of Cloud Computing [NIST 2011], this model is composed of five essential characteristics: - (On-demand self-service, Broad network access, Resource pooling, Rapid elasticity, Measured Service); three service models (Cloud Software as a Service (SaaS), Cloud Platform as a Service (PaaS), Cloud Infrastructure as a Service (IaaS)); and, four deployment models (Private cloud, Community cloud, Public cloud, Hybrid cloud). Key enabling technologies include: (1) fast wide-area networks, (2) powerful, inexpensive server computers, and (3) high-performance virtualization for commodity hardware .

Political, Economic, Social, and Technological analysis or PEST analysis - is a strategic tool for understanding market growth or decline, business position, potential and direction for operations. This tool gives SMEs an overview of the different factors that have to be taken into consideration for the development of their business strategy.

The SME definition adopted in this paper is the one concerning European Commission Recommendation 2003/361/EC [Commission 2003; Li et al. 2009].

Accordingly, CC, its services and deploying models, offers the opportunity for small businesses to subscribe to pay-per-use top class solutions at an affordable price and fulfill their operational needs to access infrastructure, platform and software over the Internet, without having to host or maintain the services themselves [Dillon et al. 2010]. Typically, some of the Cloud applications most used by SMEs are website hosting, file-server, e-mail system and related features (e.g. address book, calendar, etc.). SMEs are realizing that $\mathrm{CC}$ can have tangible benefits and are seriously considering their transition to cloud technologies [Chien et al. 2010; Sultan 2011]. 
This paper addresses the following questions:

i. What are the main factors that should be considered by SMEs when considering the strategic decision to adopt Cloud Computing, as an ICT solution?

ii. Why are these factors particularly relevant to the business processes of SMEs?

The rest of this paper is organized as follows:

Section 2 introduces CC and its main elements (e.g. architectures, security, deployment strategies) [Dillon et al. 2010]. Some Cloud Computing adoption models are described, as well the main concepts associated with them.

Section 3 explains the methodological approach of a scoping review; this was chosen as the most appropriate method to address the questions of - what and - why [Davis et al. 2009] that are at the core of this paper. The scoping review strategy is based on a protocol which includes search criteria to retrieve the most appropriate papers from the literature; first level selection was based on conventional filtering, while a hermeneutical analysis was used as a focus for second level selection [Anderson et al. 2008; Marta et al. 2011; Rumrill et al. 2010].

Section 4 presents the results obtained by applying the methods described in Section 3; these are then subjected to a PEST (political, economic, social, and technological) analysis and discussed.

Section 5 provides the Conclusions and Proposals for future work.

\section{The Adoption of Cloud Computing by SME's}

Cloud Computing was created for commercial purposes in 2007 by industry giants like Google and Amazon, Cloud Computing technology and resources are based in centralized data centers, dynamically adjusted and tuned to achieve optimum efficiency, providing an unparalleled economy of scale. The Cloud model is delivered to end users (individuals, SMEs and enterprises) as oriented pay-per-use services in which guarantees are offered by the providers by means of customized Service Level Agreements (SLAs) [Yang et al. 2009]. This converts computing power into a public utility like water, electricity or gas supplies; it is a profound paradigm change for the IT industry and possibly for society as a whole [Marta et al. 2011].

From the standpoint of an SME, the benefits of Cloud-based technologies are: low start-up costs, low cost for sporadic use, ease of management, scalability, device and location independence and rapid innovation, according to Google [TechRepublic et al. 2009]. Therefore, helping businesses to attain the benefits of $\mathrm{CC}$, by taking advantage of its potential for incremental improvement, avoids disruptive transformation of business processes [Skilton 2010]. SMEs stand to profit from pay-per-use, high performance computing scenarios [Dimitrakos 2010], enabling them to encourage innovation and enhance their competitiveness [Chen et al. 2011].

From a customer's point of view [Nair et al. 2010], the cloud computing service delivery model brings - capital expenditure reduction, increased IT agility, faster return on investment, removal of barriers to entry and a more robust and resilient infrastructure, leading to better business continuity . CC technology and services generate promising opportunities for SMEs to collaborate and create new competitive advantages in the current digital business context [Petrakou et al. 2011].

The attractiveness of Cloud Computing lies in its ability to show SME entrepreneurs immediate cost savings, increased productivity and improved responsiveness to the business, by incorporating cloud infrastructure as part of their IT strategy. According to [Tumer 2010], CC can act as a key enabler for future innovation, adding value and enhancing growth, wealth and employment in the global economy, thus creating healthy and sustainable societies.

Sections 3, 4 and 5 follow the framework for conducting a scoping review study, proposed by [Arksey et al. 2005] and later adopted by several authors, including Davis et al. [2009], Rumrill, Fitzgerald et al. [2010], Anderson et al. [2008] and Marta et al. [2011].

\section{Methodological Approach}

\section{A. Scoping Reviews/Scoping Studies}

Scoping reviews are the most appropriate R\&D methodology for [Anderson et al. 2008; Arksey et al. 2005; Levac et al. 2010; Marta et al. 2011; Rumrill et al. 2010]:

Assessing the breadth of $\mathrm{R} \& \mathrm{D}$ activities, carried out in a specific domain, as distinct from the depth;

ii) Summarizing and disseminating research results;

iii) Identifying gaps in existing research and published scientific literature;

iv) Performing a systematic review, as a methodological approach, to examine the existing literature of the domain and gather the evidence to answer the Research Question(s).

Lately, evidence-based practices are generating an increasing interest in several domains, such as the management and organizational sciences [Leana et al. 2006; Rousseau et al. 2008], computer science [Ampatzoglou et al. 2010; Esfahani et al. 2010; Oates 2006; Six et al. 2010] and software engineering [Dyba et al. 2005; Harison et al. 2010; Janzen et al. 2008; Kitchenham et al. 2007]. Taking these studies as illustrative of the application of scoping reviews, it seems to be an appropriate methodology to discover the evidence available in the literature, concerning Cloud Computing adoption and address the research questions raised here. The application of this methodological approach and the methods and techniques used to collect the data are shown in the following subsections. 
ISI Web of Knowledge-Web of Science

\begin{tabular}{l}
\hline TS=(cloud AND (SME OR small medium enterprise*)) \\
Google Scholar: \\
\hline -Cloud computing \|I AND - Technology Adoption \| AND (external environment OR external factor*) \\
AND (SME OR - small and medium enterprise* \|) \\
\hline IEEE Xplore: \\
\hline Cloud AND Adoption AND SME \\
\hline
\end{tabular}

\section{B. Paper Selection}

Taking into account the research questions and the subsequent PEST analysis, the keywords used, together with their synonymous and related terms, are those shown in the search strings developed. To perform these searches, the authors had access to the ISI Web of Knowledge -

Web of Science (WoS) [Reuters 2011], IEEE Xplore [IEEE 2011] and Google Scholar [Google 2011] databases. The following search strings were applied, these being the ones which best reflected the information required for this paper. It should be pointed out that they take account the syntax used in each of the above mentioned databases, differing on the restrictive terms according to the language specificity and search facilities of each of them. This required additional manual intervention when deciding on the inclusion or exclusion of the retrieved papers as Table 1 demonstrates:

The searches were restricted to English language documents, within the time frame 2009-2011, because Cloud Computing is a relatively recent theme which is being continuously updated.

The following exclusion criteria were used to filter the retrieved studies:

i. Paper(s) out of scope

ii. Paper(s) addressing only one of the perspectives

(Cloud Computing, SME, PEST)

iii. Paper(s) duplicated among databases

iv. References to Abstracts and Table of contents only.

The application of these criteria gave the following results (Table 1):

Table 1. Number of Papers Retrieved vs Rejected

\begin{tabular}{|c|c|c|c|}
\hline Database & Results & Excluded & Analyzed \\
\hline Web of Science & 14 & 9 & 5 \\
\hline Google Scholar & 13 & 7 & 6 \\
\hline IEEE & 41 & 31 & 10 \\
\hline Total & 68 & 47 & 21 \\
\hline
\end{tabular}

\section{c) Hermeneutic analysis}

The selected papers were subjected to hermeneutical analysis, using the software package, Atlas.ti (Version 6.2). Taking into account the requirements for PEST analysis, four codes were created, corresponding to the four different perspectives addressed by this analysis framework: political (P); economic (E); social (S); and technological (T).

The total $n^{\circ}$ of relevant papers obtained from the searches described at b) and subsequent application of the exclusion criteria defined above, was 21 . The PEST analysis using Atlas.ti software, identified the following numbers of quotes (Table 2).

\section{PEST Analysis}

To address the first question of this paper and discover some of the main factors that should be considered by SMEs when considering the strategic decision to adopt Cloud Computing, an analysis of the 21 papers retrieved based on the PEST framework was performed. The headings in the four quadrants in PEST analysis also gives a framework for reviewing the situation and describing why these factors are particularly relevant to the business processes of SMEs, thus addressing the second research question.

The main results of the PEST analysis are shown in Table 3.

Table 2. Frequency Table: Codes and Quotes by Primary Documents

\begin{tabular}{|c|c|c|c|c|c|}
\hline \multirow[b]{2}{*}{ Primary Documents } & \multicolumn{4}{|c|}{ Codes } & \multirow[b]{2}{*}{ Totals } \\
\hline & $\mathrm{P}$ & E & $\mathrm{S}$ & $\mathrm{T}$ & \\
\hline [Briscoe et al. 2009] & 9 & 2 & 11 & 3 & 25 \\
\hline [Cai et al. 2009] & 13 & 0 & 0 & 24 & 37 \\
\hline [Chen et al. 2011] & 5 & 1 & 5 & 2 & 13 \\
\hline [Chien et al. 2010] & 17 & 0 & 3 & 11 & 31 \\
\hline [Daneshgar et al. 2011] & 22 & 0 & 0 & 17 & 39 \\
\hline [Dillon et al. 2010] & 16 & 5 & 12 & 9 & 42 \\
\hline [Dimitrakos 2010] & 13 & 1 & 6 & 7 & 27 \\
\hline [Douglas et al. 2010] & 3 & 0 & 0 & 3 & 6 \\
\hline [Gagliardi et al. 2010] & 5 & 1 & 3 & 6 & 15 \\
\hline [Hanna 2010] & 7 & 2 & 2 & 4 & 15 \\
\hline [Jayakar et al. 2010] & 16 & 4 & 1 & 10 & 31 \\
\hline [Khajeh-Hosseini et al. 2010] & 4 & 0 & 2 & 7 & 13 \\
\hline [Kloch et al. 2011] & 14 & 1 & 0 & 21 & 36 \\
\hline [Levy 2009] & 1 & 0 & 0 & 1 & 2 \\
\hline [Martinovic et al. 2009] & 17 & 11 & 1 & 4 & 33 \\
\hline [Petrakou et al. 2011] & 15 & 0 & 22 & 4 & 41 \\
\hline [Sulistio et al. 2009] & 4 & 0 & 0 & 11 & 15 \\
\hline [Tumer 2010] & 9 & 3 & 6 & 6 & 24 \\
\hline [Sultan 2010] & 14 & 1 & 1 & 4 & 20 \\
\hline [Sultan 2011] & 12 & 1 & 0 & 6 & 19 \\
\hline [Williams 2009] & 15 & 8 & 18 & 12 & 53 \\
\hline Total & 231 & 41 & 93 & 172 & 537 \\
\hline
\end{tabular}


Table 3. PEST Analysis for the Adoption of Cloud Computing by SMEs

\begin{tabular}{|c|c|c|}
\hline PEST & FACTORS & AUTHORS \\
\hline \multirow{4}{*}{ 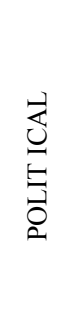 } & $\begin{array}{l}\text { Continuous data protection is provided; more legislative requirements are needed, } \\
\text { particularly those concerning the conditions under which data can be stored and } \\
\text { processed; legal definition of personal information privacy and management. }\end{array}$ & $\begin{array}{l}\text { [Gagliardi et al. 2010; Jayakar et al. 2010; } \\
\text { Martinovic et al. 2009; Sultan 2010; Tumer } \\
\text { 2010; Williams 2009] }\end{array}$ \\
\hline & $\begin{array}{l}\text { Policy initiatives to accelerate SMEs use of broadband could include favourable tax } \\
\text { treatment, in a supportive legal, political and fiscal environment. }\end{array}$ & [Jayakar et al. 2010; Martinovic et al. 2009] \\
\hline & $\begin{array}{l}\text { Politicians are looking for regulatory models as alternatives to the past monopolies, } \\
\text { recognizing that the unregulated infrastructure has lead to new kinds of monopolies, } \\
\text { controlled by the strongest service providers. }\end{array}$ & [Jayakar et al. 2010; Martinovic et al. 2009] \\
\hline & Contributes to significantly reducing carbon emissions. & [Sultan 2010] \\
\hline \multirow{11}{*}{$\sum_{\substack{0 \\
0}}^{\substack{0 \\
0}}$} & $\begin{array}{l}\text { Allows flexible payment (e.g. pay-per-use), without the need for customers to own the } \\
\text { IT infrastructure or software applications required for the business needs (SaaS- } \\
\text { Software as a service). This means that the SMEs, do not need to maintain and upgrade } \\
\text { servers, the different applications (the software) and the security. Instead, the SMEs can } \\
\text { rely on the cloud service provider that can easily scale up and down through assigning } \\
\text { and re-assigning physical and virtual resources in order to meet the actual need. }\end{array}$ & $\begin{array}{l}\text { [Briscoe et al. 2009; Cai et al. 2009; Chen et } \\
\text { al. 2011; Chien et al. 2010; Dimitrakos } \\
\text { 2010; Jayakar et al. 2010; Kloch et al. 2011; } \\
\text { Petrakou et al. 2011; Sultan 2010; Sultan } \\
\text { 2011] }\end{array}$ \\
\hline & $\begin{array}{l}\text { Allows efficient operation with a significant cost reduction/savings; cloud computing } \\
\text { solutions will minimize the SMEs investment in own hardware (HW), software (SW) } \\
\text { and maintenance. }\end{array}$ & $\begin{array}{l}\text { [Cai et al. 2009; Chien et al. 2010; Jayakar } \\
\text { et al. 2010; Kloch et al. 2011; Sultan 2010] }\end{array}$ \\
\hline & $\begin{array}{l}\text { Due to the limited financial power of SMEs in comparison with large organizations, the } \\
\text { cost factor seems to be even more relevant to the SMEs (they have a technical and } \\
\text { financial lack of resources when compared with large companies). }\end{array}$ & $\begin{array}{l}\text { [Chien et al. 2010; Daneshgar et al. 2011; } \\
\qquad \text { Sultan 2010] }\end{array}$ \\
\hline & $\begin{array}{l}\text { Strategy and competitive advantage does not seem to be as relevant to the SMEs as it } \\
\text { may be to the larger organization, because their strategy is life-time rather than } \\
\text { short-time. }\end{array}$ & [Daneshgar et al. 2011; Jayakar et al. 2010] \\
\hline & $\begin{array}{l}\text { Many SMEs do not have the knowledge of IS and IT and all its_topics ', making any } \\
\text { decision dependent upon outside IT vendor organisations. }\end{array}$ & [Hanna 2010] \\
\hline & $\begin{array}{l}\text { The ongoing economic crisis has prompted responses by governments to limit economic } \\
\text { effects of the credit crunch; the crisis should not damage the drivers of long-term } \\
\text { growth. As result SMEs should invest in smart infrastructure and green technology. }\end{array}$ & [Hanna 2010] \\
\hline & The need for regular new software purchases is reduced or eliminated. & [Jayakar et al. 2010] \\
\hline & $\begin{array}{l}\text { In terms of ongoing cost/productivity of companies ' improvements, it estimates a } \\
50-75 \% \text { reduction in the time and effort it takes to add new products. }\end{array}$ & [Jayakar et al. 2010] \\
\hline & $\begin{array}{l}\text { Greater security is possible due to economies of scale and the ability to afford better } \\
\text { security experts. }\end{array}$ & $\begin{array}{l}\text { [Chien et al. 2010; Jayakar et al. 2010; } \\
\text { Kloch et al. 2011; Levy 2009; Sulistio et al. } \\
\text { 2009] }\end{array}$ \\
\hline & $\mathrm{CC}$ encourages innovation and enhances business competitiveness & $\begin{array}{l}\text { [Dimitrakos 2010; Tumer 2010; Williams } \\
\text { 2009] }\end{array}$ \\
\hline & $\begin{array}{l}\text { In general, cloud-computing services provide an open business platform for everyone, } \\
\text { everywhere, for every country, for every company, for every organization and for every } \\
\text { kind of business. }\end{array}$ & [Kloch et al. 2011; Sultan 2010] \\
\hline \multirow{5}{*}{ 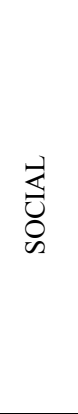 } & User friendliness. & [Daneshgar et al. 2011] \\
\hline & $\begin{array}{l}\text { New opportunities for collaboration and social networking between business partners by } \\
\text { enabling access to sources of information that are time and distance independent. }\end{array}$ & $\begin{array}{l}\text { [Dimitrakos 2010; Gagliardi et al. 2010; } \\
\text { Martinovic et al. 2009; Petrakou et al. 2011; } \\
\text { Tumer 2010; Williams 2009] } \\
\end{array}$ \\
\hline & $\begin{array}{l}\text { A community of local players, together with distributed virtual communities, contributes } \\
\text { to the development of strategies, technological solutions, digital services and business } \\
\text { models. }\end{array}$ & [Gagliardi et al. 2010] \\
\hline & $\begin{array}{l}\text { Opportunity for support managers, engineers, sales and marketing staff to develop new } \\
\text { skills; working with new and potentially prestigious technology, which may lead to } \\
\text { career progression and increased job satisfaction. }\end{array}$ & [Khajeh-Hosseini et al. 2010] \\
\hline & Cooperation in information technology. & [Chen et al. 2011; Williams 2009] \\
\hline \multirow{5}{*}{ 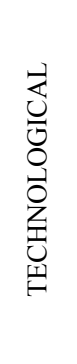 } & Provides a certain level of customization and allows an efficient operation. & [Cai et al. 2009] \\
\hline & Provides flexible response to change. & $\begin{array}{l}\text { [Chien et al. 2010; Daneshgar et al. 2011; } \\
\text { Kloch et al. 2011; Sulistio et al. 2009] }\end{array}$ \\
\hline & Reliability is improved through the use of redundant sites. & $\begin{array}{l}\text { [Daneshgar et al. 2011; Kloch et al. 2011; } \\
\quad \text { Sulistio et al. 2009; Sultan 2010] }\end{array}$ \\
\hline & $\begin{array}{l}\text { Scalability is offered through dynamic provisioning of resources. Capacity scaling is } \\
\text { done in the cloud, and not at the customer premises. }\end{array}$ & $\begin{array}{l}\text { [Chien et al. 2010; Daneshgar et al. 2011; } \\
\text { Khajeh-Hosseini et al. 2010; Kloch et al. } \\
\text { 2011; Sulistio et al. 2009] }\end{array}$ \\
\hline & $\begin{array}{l}\text { Service with high quality, always accessible anytime, at any device (mobile and fixed), } \\
\text { at any connection (via fixed and wireless connections) and from any place. }\end{array}$ & $\begin{array}{l}\text { [Briscoe et al. 2009; Kloch et al. 2011; } \\
\text { Sultan 2010] }\end{array}$ \\
\hline
\end{tabular}




\begin{tabular}{|c|c|}
\hline $\begin{array}{l}\text { SMEs do not need to maintain and upgrade servers, applications (the software) and } \\
\text { security. }\end{array}$ & $\begin{array}{l}\text { [Kloch et al. 2011; Petrakou et al. 2011; } \\
\qquad \text { Sultan 2010] }\end{array}$ \\
\hline $\begin{array}{l}\text { Governance of network and IT state, flexible license management models, } \\
\text { understanding of how operations perform according to Service Level Agreements (SLA) }\end{array}$ & [Dillon et al. 2010] \\
\hline $\begin{array}{l}\text { Basic generic services include systems for electronic payment, for certification and trust, } \\
\text { enterprise resource planning, customer relationship management, e-procurement. }\end{array}$ & $\begin{array}{l}\text { [Gagliardi et al. 2010; Tumer 2010; } \\
\text { Williams 2009] }\end{array}$ \\
\hline $\begin{array}{l}\text { The launch requires minimal effort due to the easy migration of code to the new } \\
\text { environment. }\end{array}$ & $\begin{array}{l}\text { [Chien et al. 2010; Dillon et al. 2010; Sultan } \\
\text { 2010] }\end{array}$ \\
\hline
\end{tabular}

Table 3 presents a baseline with the contributions of the $\mathrm{v}$. primary documents used for mapping the PEST analysis. vi. The conclusions and future work discussed in the next vii. Section are grounded on results contained in this table, expressing the political, economic, social and technological viii. factors related with the adoption of CC by SMEs.

\section{Discussion and Conclusions, Future Work}

The experiences of SMEs investing in innovative technologies, such as Cloud Computing, should provide additional evidence concerning patterns of adoption [Levy 2009]. It becomes obvious from the PEST analysis that the emerging systems of Cloud Computing have the potential to multiply the productivity, efficiency and profitability of small scale enterprises. However, some SMEs remain reluctant to avail themselves of broadband services, or consider the possible advantages of Cloud Computing, due to perceptions (or misconceptions) regarding possible capital investment, fear of complexity, lack of understanding of the potential benefits, and lack of technical resources. Others are more willing to test broadband or Cloud applications, but do not see it as part of a larger strategy [Jayakar et al. 2010]. Evidence is also emerging to suggest that even large companies (contrary to conventional wisdom) are actually embracing Cloud services. Consequently, an increasing number of companies (small and large) are beginning to see some real value in using the Cloud [Sultan 2010].

There are many opportunities and advantages for SMEs in using Cloud Computing, such as opportunities to test new software, evaluate third party applications, increase resources on demand to satisfy seasonal or temporary demand and offer software to customers as SaaS. Other benefits include time saved dealing with technology issues, allowing staff to focus on core competencies. Many of the same functions can be performed faster and more efficiently by using modern IT infrastructure and software than traditional in-place data centers. As a result, Cloud computing is likely to be an attractive option for many SMEs, particularly in the current global economic crisis, due to its flexible cost structure and scalability.

Cloud Computing fits specific SMEs needs as follows:

i. Being available off the shelf;

ii. User friendliness;

iii. Ubiquitous systems;

iv. Low price;
Having a variety of options to choose from;

Customer support/communication;

Availability of staff to work with and maintain the

system;

Strategic impact;

ix. Software already existing to implement customizable

Enterprise Resource Planning (ERP);

x. Existence - at least in some countries - of

Government/tax regulation and policies that support

IT projects based on Cloud computing.

In the specific case of SMEs, access to Cloud services is becoming a critical element for their competitiveness and efficiency. Conversely, lack of access would imply that the SME sector will not achieve its full potential. In general, Cloud Computing services provide an open business platform for everyone, everywhere, for every country, for every company, for every organization and for every kind of business and new opportunities for collaboration and social networking between business partners, by enabling access to sources of information that are time and distance independent.

The PEST factors, combined with external micro-environmental factors and internal drivers, can be viewed as a combination of both opportunities and threats. Nevertheless, this methodology addresses only external factors and their influence on organizations ' behavior not taking into account the role that internal variables can play in this context. In this sense and for future research, a SWOT analysis is recommended, when studying the mix of internal and external factors concerning the adoption of Cloud Computing by SMEs.

\section{REFERENCES}

[1] Ampatzoglou, A., \& Stamelos, I. (2010). Software engineering research for computer games: A systematic review. Information and Software Technology, 52(9), 888-901.

[2] Anderson, S., Allen, P., Peckham, S., \& Goodwin, N. (2008). Asking the right questions: scoping studies in the commissioning of research on the organisation and delivery of health services. Health Res Policy Syst, 6, 7.

[3] Arksey, H., \& O'Malley, L. (2005). Scoping studies: towards a methodological framework.

[4] International Journal of Social Research Methodology, 8(1), $19-32$. 
[5] Briscoe, G., \& Marinos, A. (2009). Digital ecosystems in the clouds: Towards community cloud computing. Paper presented at the 3rd IEEE International Conference on Digital Ecosystems and Technologies, DEST'09, 1-3 June.

[6] Cai, H., Zhang, K., Zhou, M. J., Gong, W., Cai, J. J., Mao, X. S., et al. (2009). An End-to-End Methodology and Toolkit for Fine Granularity SaaS-ization. Paper presented at the Cloud: 2009 IEEE International Conference on Cloud Computing, 21-25 Sept.

[7] Chen, J., \& Song, H. (2011). Industrial clusters' information based on SaaS model. Paper presented at the International Conference on Business Management and Electronic Information (BMEI), 13-15 May.

[8] Chien, C. S., \& Chien, J. (2010). Insight to Cloud Computing and Growing Impacts Information Computing and Applications (Vol. 105), Springer, pp. 250-257.

[9] Commission, E. (2003). Commission Recommendation of 6 May 2003 concerning the definition of micro, small and medium-sized enterprises (SMEs). Retrieved 13 June 2011, from http://ec.europa.eu/enterprise/policies/sme/facts-figures -analysis/sme-definition/index_en.htm

[10] Daneshgar, F., Worasinchai, L., \& Low, G. (2011). An Investigation of 'Build vs. Buy'Decision for Software Acquisition in Small to Medium Enterprises. Paper presented at the Society of Interdisciplinary Business Research (SIBR) 2011 Conference on Interdisciplinary Business Research, 16-18 June.

[11] Davis, K., Drey, N., \& Gould, D. (2009). What are scoping studies? A review of the nursing literature. [Review]. International Journal of Nursing Studies, 46(10), 1386-1400.

[12] Dillon, T., Chen, W., \& Chang, E. (2010). Cloud Computing: Issues and Challenges. Paper presented at the 24th IEEE International Conference on Advanced Information Networking and Applications (AINA), 20-23 April.

[13] Dimitrakos, T. (2010,). Common Capabilities for Service Oriented Infrastructures and Platforms: An Overview. Paper presented at the IEEE 8th European Conference on Web Services (ECOWS), 1-3 Dec.

[14] Douglas, A., Wainwright, D., \& Greenwood, D. (2010). The Dynamics of IT Supplier Relationships with Construction SMEs: a Technological Frames Approach. Paper presented at the UK Academy for Information Systems Conference Proceedings 2010. Paper 20.

[15] Dyba, T., Kitchenham, B. A., \& Jorgensen, M. (2005). Evidence-based software engineering for practitioners. Software, IEEE, 22(1), 58-65.

[16] Esfahani, H. C., Yu, E., \& Cabot, J. (2010). Situational evaluation of method fragments: an evidence-based goal-oriented approach. Paper presented at the 22nd international conference on Advanced information systems engineering, 29 April.

[17] Gagliardi, R., Marcantoni, F., Polzonetti, A., Re, B., \& Tapanelli, P. (2010). Cloud computing for network business ecosystem. Paper presented at the IEEE International Conference on Industrial Engineering and Engineering Management (IEEM), 7-10 Dec.

[18] Google. (2011). Google Scholar. from $\mathrm{http}: / /$ scholar.google.com/
[19] Hanna, N. K. (2010). A Holistic Framework for Enterprise and Social Transformation. Enabling Enterprise Transformation, 217-266.

[20] Harison, E., \& Koski, H. (2010). Applying open innovation in business strategies: Evidence from Finnish software firms. Research Policy, 39(3), 351-359.

[21] IEEE. (2011). IEEE Xplore Digital Library. from $\mathrm{http}$ //ieeexplore.ieee.org/

[22] Janzen, D. S., \& Ryoo, J. (2008 ). Seeds of Evidence: Integrating Evidence-Based Software Engineering. Paper presented at the 21st Conference on Software Engineering Education and Training, 14-17 April.

[23] Jayakar, K., Schejter, A., \& Taylor, R. ( 2010). Small businesses and broadband: Key drivers for economic recovery.Unpublished manuscript, University Park, PA.

[24] Khajeh-Hosseini, A., Greenwood, D., \& Sommerville, I. (2010). Cloud Migration: A Case Study of Migrating an Enterprise IT System to IaaS. Paper presented at the IEEE 3rd International Conference on Cloud Computing (CLOUD), 5-10 July.

[25] Kitchenham, B., \& Charters, S. (2007). Guidelines for performing systematic literature reviews in software engineering. Engineering, 2(EBSE 2007-001).

[26] Kloch, C., Petersen, E. B., \& Madsen, O. B. (2011). Cloud Based Infrastructure, the New Business Possibilities and Barriers. Wireless Personal Communications, 58(1), 17-30.

[27] Leana, C. R., \& Pil, F. K. (2006). Social capital and organizational performance: Evidence from urban public schools. Organization Science, 17(3), 353.

[28] Levac, D., Colquhoun, H., \& O'Brien, K. K. (2010). Scoping studies: advancing the methodology. Implementation Science, $5(1), 9$.

[29] Levy, M. (2009). An exploration of the role of information systems in developing strategic growth in small and medium-sized enterprises. University of Warwick, Warwick.

[30] Li, L., Zheng, Y., Zheng, F., Zhong, S., \& Ieee. (2009). Cloud Computing Support for Personal Knowledge Management. Paper presented at the International Conference on Information Management and Industrial Engineering, 26-27 Dec.

[31] Marta, F. C., Correia, A. M. R., \& Neves, F. T. (2011,). Supporting KMS through Cloud Computing: a scoping review. Paper presented at the 6th Iberian Conference on Information Systems and Technologies (CISTI), Chaves, 15-18 June.

[32] Martinovic, D., \& Ralevich, V. (2009). Canadian and UK perspectives on electronic business data transfer. Paper presented at the IEEE Toronto International Conference on Science and Technology for Humanity (TIC-STH), Toronto, 26-27 Sept.

[33] Nair, S. K., Porwal, S., Dimitrakos, T., Ferrer, A. J., Tordsson, J., Sharif, T., et al. (2010).

[34] Towards Secure Cloud Bursting, Brokerage and Aggregation. Paper presented at the IEEE 8th European Conference on Web Services (ECOWS), 1-3 Dec.

[35] NIST. (2011). The National Institute of Standards and 
Technology (NIST). Retrieved 11 June, 2011, from http://www.nist.gov/itl/cloud/

[36] Oates, B. J. (2006). Researching Information Systems and Computing: SAGE.

[37] Petrakou, A., Brandt, P., Gustavsson, R., \& Jokela, P. (2011). Collaborative e-Marketplaces Containing Clusters of SMEs: Drivers and Barriers in the Local Food Sector. Paper presented at the 44th Hawaii International Conference on System Sciences (HICSS), 4-7 Jan.

[38] Reuters, T. (2011). ISI Web of Knowledge - Web of Science. from http://apps.isiknowledge.com/

[39] Rousseau, D. M., Manning, J., \& Denyer, D. (2008). Evidence in management and organizational science: Assembling the field's full weight of scientific knowledge through syntheses. Academy of Management Annals, 2(1), 475-515.

[40] Rumrill, P. D., Fitzgerald, S. M., \& Merchant, W. R. (2010). Using scoping literature reviews as a means of understanding and interpreting existing literature. [Article]. Work-a Journal of Prevention Assessment \& Rehabilitation, 35(3), 399-404.

[41] Sheng-Yuan, Y., Chun-Liang, H., \& Dong-Liang, L. (2010). An ontology-supported ubiquitous interface agent for cloud computing: Example on Bluetooth wireless technique with Java programming. Paper presented at the International Conference on Machine Learning and Cybernetics (ICMLC), 11-14 July.

[42] Six, B. L., Schap, T. R. E., Zhu, F. M., Mariappan, A., Bosch, M., Delp, E. J., et al. (2010). Evidence-based development of a mobile telephone food record. Journal of the American Dietetic Association, 110(1), 74-79.
[43] Skilton, M. (2010). Building Return on Investment from Cloud Computing. Retrieved from http://www.opengroup.or $\mathrm{g} / \mathrm{cloud} /$ whitepapers/ccroi/index.htm

[44] Sulistio, A., Reich, C., \& Doelitzscher, F. (2009). Cloud Infrastructure \& Applications - CloudIA. In M. G. Jaatun, G. Zhao \& C. Rong (Eds.), Cloud Computing (Vol. 5931), pp. 583-588.

[45] Sultan, N. (2010). Cloud computing for education: A new dawn? International Journal of Information Management, 30(2), 109-116.

[46] Sultan, N. (2011). Reaching for the "cloud": How SMEs can manage. International Journal of Information Management, 31(3), 272-278.

[47] TechRepublic, ZDNet, \& BNET. (2009). Cloud Computing -What is its Potential Value for Your Company? Retrieved from http://www.techrepublic.com/whitepapers/cl oud-computing-what-is-its-potential-value-for-your-compan $\mathrm{y} / 1130965$

[48] Tumer, O. S. (2010). Digital ecosystems \& Co-innovation towards sustainable societies. Paper presented at the 4th IEEE International Conference on digital Ecosystems and Technologies (DEST), 13-16 April.

[49] Williams, M. A. (2009). Privacy Management, the Law and Business Strategies: A Case for Privacy Driven Design. Paper presented at the CSE'09. International Conference on Computational Science and Engineering, 2009, 29-31 Aug.

[50] Yang, H., \& Tate, M. (2009). Where are we at with Cloud Computing? A Descriptive Literature Review. Paper presented at the 20th Australasian Conference on Information Systems, Melbourne, 2-4 Dec. 